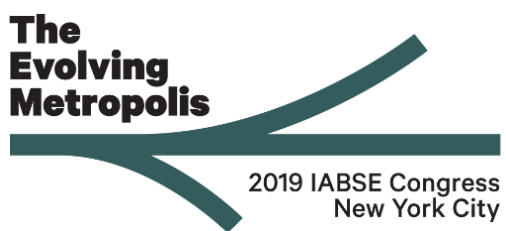

\title{
Risk and resilience of bridgeworks exposed to hydraulic hazards
}

\author{
Stergios A MITOULIS \\ associate professor \\ University of Surrey \\ Guildford, UK \\ s.mitoulis@surrey.ac.uk
}

Expert in risk and resilience of transport assets; monitoring-

driven resilience of

infrastructure; damage-free, zero-maintenance bridges,

Eurocode expert, leader of infrastructuResilience.com

\author{
Sotirios A ARGYROUDIS \\ Marie-Curie fellow \\ University of Surrey \\ Guildford, UK \\ s.argyroudis@surrey.ac.uk
}

Expert in vulnerability and risk assessment of transportation infrastructure exposed to multiple hazards; resilience assessment of infrastructure

\author{
Rob LAMB \\ professor \& director \\ Lancaster Uni \& JBA \\ Skipton, UK \\ Rob.Lamb@jbatrust.org \\ R\&D on flooding and risk \\ analysis, state of-the-art \\ methods for risk analysis in \\ flood management
}

Contact: s.mitoulis@surrey.ac.uk

\section{Abstract}

Transportation infrastructure is a pylon for the society and economy, enabling the services and transportation of goods, under normal and emergency circumstances. Bridgeworks act as bottlenecks within road and rail networks and their failures due to e.g. floods, cause disproportionate losses, which are expected to be exacerbated due to climate change. Thus, pinpointing the vulnerabilities and quantifying the resilience of bridges within transportation networks exposed to hydraulic hazards is of paramount importance. However, reliable quantification of risk and resilience of flood-critical bridges is not yet available, as there is a lot of engineering guesswork for qualitative assessments. This paper describes a new integrated framework for the resilience assessment of bridgeworks and networks subjected to hydraulic hazards such as scour, debris flow and hydraulic actions. An overview of the critical hydraulic hazards, and the evaluation of their intensity measures based on regional and site-specific approaches is provided in the paper. The framework also includes vulnerability models for bridges for the evaluation of direct losses, i.e. physical damage, as a means to deliver the quantitative risk assessment (QRA) of the exposed bridgeworks and networks. The second component of the resilience framework is the restoration and reinstatement models, which are expressed by practical restoration times and tasks. Toward this end, this paper summarises an on-going comprehensive survey, which aims to elicit knowledge from experts, in an effort to develop restoration models for bridges exposed to floods. The framework is a useful tool for allocating the resources reasonably toward efficient management and consequence analysis on a network level.

Keywords: bridges; network; transport; infrastructure; fragility; risk; resilience; flood; scour; assessment

\section{Introduction}

Flooding is the greatest risk to infrastructure assets and to bridges all over the world. The cause that accounts for the largest percent of recorded bridge failures is of hydraulic nature, and in particular scour (S) that is triggered by floods, debris accumulation (D) and hydraulic forces (F), which may be exacerbated due to climate change [1]. Based on a record of scour-induced bridge failures spanning over 173 years, it is estimated that the annual probability of failure is $27 \%$, i.e. one out of three bridges crossing watercourse might be damaged due to flood [2]. There has been extensive research on hydraulic actions (SDF) to transport infrastructure, including numerical [3][4], experimental [5] and monitoring [6] efforts. 
Furthermore, there are available guidelines for the design and assessment of bridges exposed to hydraulic (SDF) actions [7]. However, very little research is available on quantitative risk and vulnerability assessment of bridges exposed to SDF [4][8], whilst no research is available for assessing the resilience of flood-critical bridges, even though it is widely recognised that Quantitative Risk Analysis (QRA) is important, especially for the resilience and adaptability of critical assets [9][10]. This is a capability gap that needs filling with new and reliable fragility and restoration functions which can reflect realistically, the rapidity of the recovery and the reinstatement actions required throughout the post-disaster management actions [11]. It is clarified here that restoration tasks are assumed to include, to some extent, structural interventions, e.g. strengthening of a scoured foundation, whereas reinstatement tasks refer to non-structural interventions, e.g. removal of debris from the bridge deck.

Practical restoration models toward the quantification of bridge resilience, require a good understanding and modelling of the type and extent of damage due to SDF actions and depend on the available resources, e.g. funds, materials, equipment and labour, and the uncertainties during the restoration process, e.g. the preparedness and other organisational factors. The modelling of such a complex technical and financial task can be based on the literature, statistics and experts' elicitation. To date, restoration functions of scoured bridges have not been produced. On the basis of this established knowledge gap, this paper presents an integrated framework for quantifying the bridge and network resilience for flood-induced damages and summarises an on-going comprehensive survey, which elicits knowledge from experts in an effort to develop restoration and reinstatement models. This first effort of data collection is not a complete one, yet useful conclusions are extracted, and insights were gained with regard to the feasibility of producing reliable resilience models for representative bridges.

\section{Resilience framework}

The framework for quantifying the bridge and network resilience for flood-induced damages is described in Figure 1. It includes four distinct steps:
Step 1 is the definition of the flood actions and the selection of intensity measures (IMs). More specifically, for each bridge of the road network, the probability of exceedance for a certain IM can be calculated with either regional flood hazard curves or with site-specific hazard analysis. For ungauged sites, regional regression equations can be utilised for estimating streamflow statistics [12]. The resulting hazard maps or curves should correlate the IMs, e.g. peak water discharge, with the flood annual exceedance probabilities for different return periods (e.g. 2, 5, 50, 100, 500 years). Subsequently, the hydraulic actions and the IM must be defined; further information is provided in section 4 below. Step 2 includes the quantification of the risk by means of fragility curves and the rapidity of restoration with restoration models. For this purpose, the bridge typologies and the failure modes are defined, on the basis of identified vulnerability parameters, e.g. type of pier and abutment, deck, number of spans, lengths and foundation type. At this stage, it is important to understand that the failure modes include, in many cases, combinations of structural and geotechnical failures. Thus, it is essential to model and validate FE models that are able to capture compatible modes of damage related to the capacity of the bridge and the flooded/scoured foundation. Fragility curves, which describe the probability of exceeding certain damage states (minor, moderate, extensive, complete) are defined based on probabilistic correlations between engineering demand parameters (EDPs) and IMs. EDPs describe the performance of the bridge components based on the modelling results [13][14]. Fragility models can be adaptive, to account for: (a) deterioration, e.g. cumulative scour \& ageing, (b) improvements with mitigation measures, e.g. rip-rap. Step 3 includes the resilience-based management of the road networks, after convoluting the hazard (step 1 ), the bridge fragility and the restoration (step 2) of the exposed assets based on traffic analysis. This step considers the post-disaster evolution of the origin-destination (OD) matrix, as this is dependent on the damaged bridge (partial/full) closures. In particular, traffic analyses are employed on the basis of dynamic adaptation of the OD matrices, prior to and after the flood, considering the gradual bridge repair and opening and the network functionality recovery (restoration matrix) [15]. 
Finally, in step 4, the critical bridges are defined based on their impact on the cost and downtime during the restoration of the road network functionality, in light of the resilience objectives set by the stakeholder. Also, potential pre-disaster mitigation methods, in terms of bridge retrofitting and scour prevention, and the organisation of the post-disaster recovery plans that can maximise the resilience of the network, are evaluated.

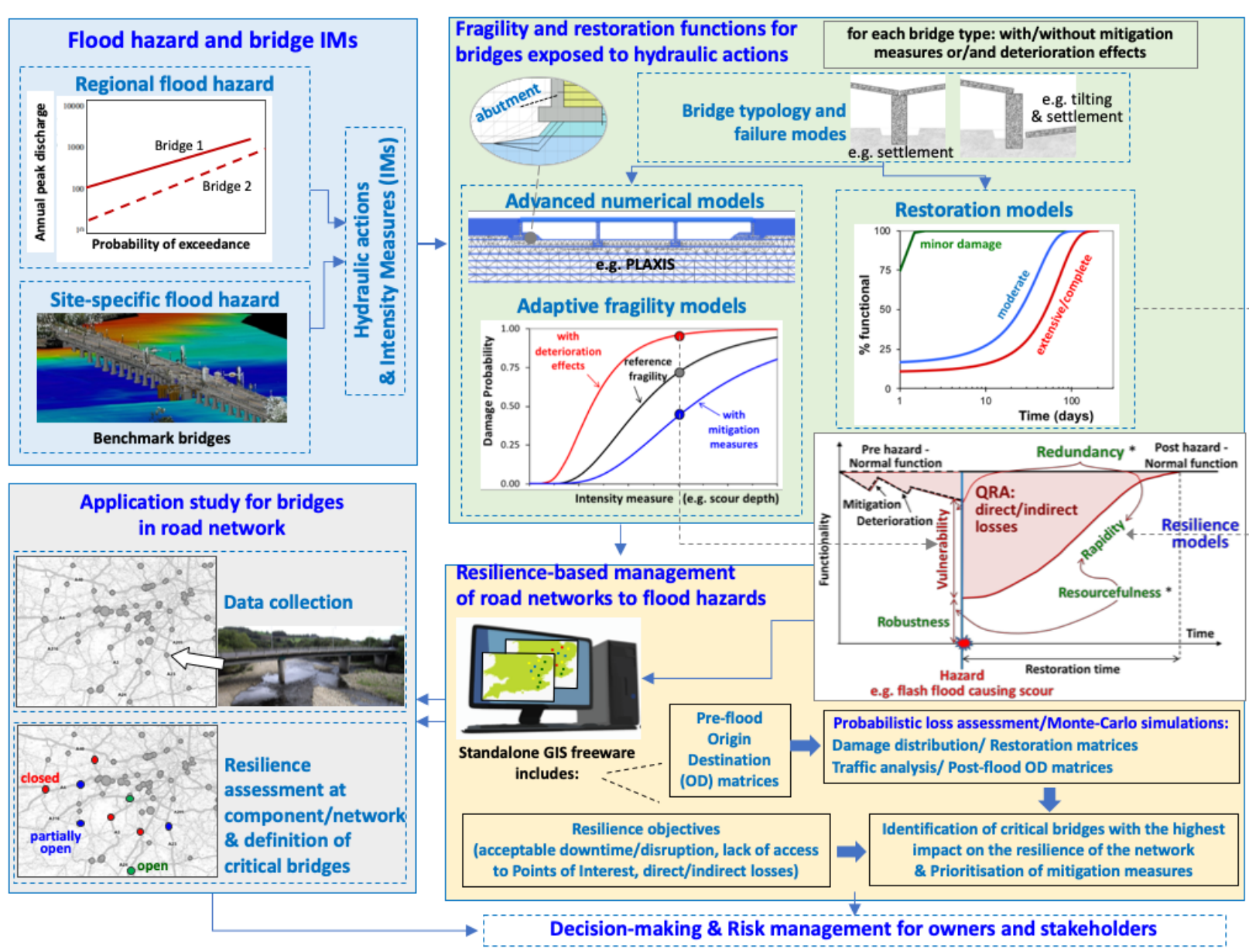

* Redundancy and Resourcefulness enhance Rapidity and Robustness and thus reduce the Vulnerability of bridges and transportation networks

Figure 1. Framework for quantifying the risk and resilience of scour-critical bridges and road networks

\section{Hydraulic hazards and intensity measures}

This section provides an overview of the critical hydraulic hazards, and the evaluation of their intensity measures based on regional and sitespecific approaches. The critical hydraulic hazards for bridges are scour, debris impacts and hydraulic forces. The fundamental source of risk in all three of the above cases is the potential for flow conditions that exceed the capacity of the bridge. A probabilistic risk analysis is a rational strategy to manage uncertainties due to weather and climatic variability and the uncertainty about the response of the bridge.

There are numerous metrics that could be chosen to describe the hazard intensity related to hydraulic loading. Possible intensity measures (IMs) include characteristics of the flow itself (e.g. peak flow rate, velocity, water depth), and features related to debris (e.g. volume, type, size distribution, sources) and/or depth and extent of scour depth. It is not obvious what is the best choice of intensity measures to balance practicality and rigour. To address this issue, Lamb et al. [16] applied a formal process of expert elicitation to draw out a synthesis of current knowledge. A categorical approach, the 
method of paired comparison [17][18], was used to examine which factors determine the likelihood of scour at a bridge, and how the experts thought those factors should be ranked in importance (Table 1). The findings of the elicitation were well-aligned with current UK industry guidance on scour assessment, highlighting the importance of bridge foundation depth, measured or predicted scour depths, river typology (e.g. gradient, sinuosity), foundation material (e.g. clay, rock or of unknown type). Additionally, the elicitation identified other factors that are potentially important in assessing scour risk. These factors highlight the potential influence of changes to a watercourse at and around a bridge, including dredging or sand/gravel extraction, river restoration actions and the influence of flood defenses.

Table 1. Loading conditions for bridge scour IMs ranked in descending order of importance

\begin{tabular}{ll}
\hline rank & potential IM \\
\hline 1 & frequency and amount of debris \\
\hline 2 & peak flow \\
\hline $4=$ & flow return period \\
\hline $4=$ & $\begin{array}{l}\text { time during which flow is greater than a } \\
\text { critical threshold for scour initiation }\end{array}$ \\
\hline $6=$ & peak water level \\
\hline $6=$ & $\begin{array}{l}\text { time during which level is greater than a } \\
\text { critical threshold for scour initiation }\end{array}$ \\
\hline 8 & $\begin{array}{l}\text { number of high flows (capable of causing } \\
\text { scour) in last year }\end{array}$ \\
\hline 9 & $\begin{array}{l}\text { sediment concentration reaching the bridge } \\
\text { at high flows }\end{array}$ \\
\hline
\end{tabular}

The elicitation also considered potential IMs relating to hydraulic conditions during flood events. Flood flow rate and duration, flow velocities around the structure and morphological stability were consistently ranked by the group as important in determining scour vulnerability. However, there was considerable ambiguity about the relative importance of many other factors, supporting the application of multi-factorial approaches to risk assessment. In addition to variables expressed on physical scales, the return period, or exceedance probability, of a flood event ranked highly as one approach to defining a generic IM for the development of bridge scour fragility functions. This use of a probabilistic IM has the advantage that it is essentially a non-dimensional measure, although defined with respect to a reference time scale, e.g. annual probability, which may be translated into a return period, nominally having units of time. In addition to IMs that capture instantaneous flow conditions, the expert elicitation also identified a set of potential IMs that would take account of the dynamic nature of hydraulic loading and bridge vulnerability, including event duration, i.e. the time during a "load event", in which flow or water levels exceed a critical threshold and the cumulative effect of sequences of loading events over a given reference time scale.

For the simple IMs, related to peak flow, regionalised estimates may be possible based on standard hydrological models [12]. Flood mapping studies that model the areas of inundation for prescribed exceedance probability events may offer a first approximation of potential water levels, especially where they have been derived from highresolution LIDAR survey. Although a local channel and structure survey is necessary to obtain precise estimates of levels, velocities and other hydraulic IMs, there may be potential to generalise results based on empirical studies that seek to relate hydraulic geometry to flow rate [19][20][21][22]. Such estimates should not be treated as deterministic functions owing to their empirical basis and associated statistical uncertainty. The limitations inherent in hydraulic geometry to flow relations have been highlighted by Soar and Thorne [23], who looked at the simplification of a complex system in which the effects of various factors are difficult to separate. It is worth noting that the probabilistic analysis of instantaneous IMs is wellsupported by standard hydrological methods, such as the fitting of univariate extreme value distributions. However, IMs taking account of load event duration or sequencing would require more sophisticated probabilistic analysis to account for temporal dependence and clustering.

\section{Restoration models}

The generation of restoration functions, which correlate the level of the restored functionality with time after the commencement of repair works (i.e. rapidity of recovery), should consider the type and extent of damage, the available resources, the local practices and the associated uncertainties. Due to 
the acknowledged absence of restoration models of flood-induced damages on bridges, a comprehensive questionnaire was prepared, and a survey was conducted as a means to develop restoration functions for bridges. In what it follows, a brief description of the survey questionnaire is given. The findings are expected to inform county councils, owners and stakeholders and provide valuable information for managing efficiently their assets prior and after catastrophic events.

The first part of the survey contains a number of questions including a self-assessment of the expert's knowledge and professional experience on flood-induced bridge damages and restoration after floods. This provided measures of experts' confidence. The questionnaire includes a breakdown of 22 restoration tasks for the bridge foundations, piers, abutments \& wingwalls, bearings, deck, and the backfill with the approach slab. Additional tasks may be added by the experts. Indicative restoration tasks are flow-altering, removal of debris, temporary support of one pier etc. The experts are expected to provide to the best of their knowledge the maximum and minimum time required for each one of the restoration tasks. The questionnaire covers the restoration tasks of any river crossing bridge with spread or piled foundations. The deck of the bridge is considered to be either continuous or simply-supported. The pier to deck and abutment to deck connection is considered to be either rigid or through bearings. The number of spans and the geometry of each structural component were not considered in this questionnaire due to their variability. The experts are requested to provide for each level of damage, i.e. minor, moderate, extensive complete, the idle time, i.e. the lag, before the commencement of any restoration task. Subsequently, for each structural component and for each damage level the percentage of the traffic capacity of the bridge expected to be given for restoration times of $0,1,3$, $7,30,60,90,180,270$ and 365 days, where 0 is the day of the commencement of the restoration tasks, meaning that, for each damage level, the prospected loss of traffic capacity of the bridge is expected to be elicited. The experts are also requested to prioritise the restoration tasks and to provide a cost ratio as a percentage of the cost of replacement. The above tasks and traffic capacity estimates are guided by sketches and quantitative description of damages for each bridge component. Indicatively, Figure 2 illustrates the extensive damage of a spread foundation to flood-induced scour, whilst the participants of the survey are also given a scour hole depth of 1.5 to $2.0 \mathrm{Df}$, maximum settlement of $50-130 \mathrm{~mm}$, a footing rotation of 4$6 \%$, and a potential shear failure with crack widths ranging between 0.6 to $3 \mathrm{~mm}$ and/or reinforcement yielding. The foundation is expected to have a FoS in the range of 1 . All the above are well informed criteria that the spread foundation is structurally and/or geotechnically insufficient to carry the bridge loads and thus restoration is required.

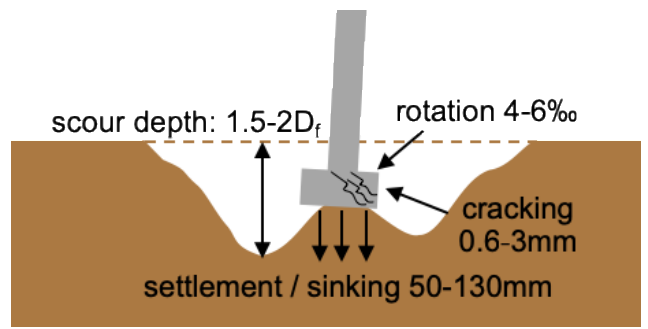

Figure 2. Extended damage for hydraulic induced damage to spread foundations

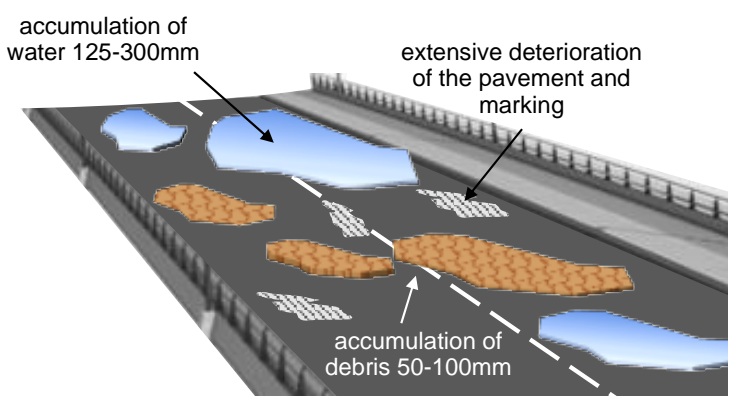

Figure 3. Extended functionality loss for hydraulic induced disruptions to bridge deck

In addition, restoration times for hydraulic induced disruptions to bridge deck due to non-structural effects are elicited (Figure 3). In this case, functionality loss levels are defined based on the accumulation of water due to overtopping, the accumulation of debris due to landsliding of adjacent slopes or flooding, and the deterioration of the pavement.

\section{Conclusions}

An integrated framework for the resilience assessment of bridges and networks subjected to hydraulic hazards was described, including the evaluation of their intensity measures based on regional and site-specific approaches. The 
framework provides the means to deliver quantitative risk and resilience assessments of the exposed bridgeworks and networks on the basis of vulnerability, restoration and reinstatement models. The only way for reliable restoration models is to collect opinions from experts considering the type and extent of damage, local practices and other organisational factors. Toward this end, a novel comprehensive survey, which aims to elicit knowledge from experts, in an effort to develop restoration models for bridges exposed to floods was presented. The framework is a useful tool for allocating the resources reasonably toward efficient management on a network level.

\section{References}

[1] R. Pant et al. 'Critical infrastructure impact assessment due to flood exposure', J Flood Risk Manage, 11:22-33, 2018.

[2] Z. van Leeuwen, R. Lamb, 'Flood and scour related failure incidents at railway assets, UK', JBA Trust, Prj W13-4224, 2014.

[3] H. Kim $\mathrm{H}$ et al. 'Flood fragility analysis for bridges with multiple failure modes, $A d v$ Mech Eng, 9(3), 2017.

[4] J.V. Klinga, A. Alipour, 'Assessment of structural integrity of bridges under scour', Eng Struct, 82, 2015.

[5] M. Roca, R. Whitehouse, Scour risk assessment at river crossings. Proc. ICSE6, Paris, 2012.

[6] L.J. Prendergast, K. Gavin, 'A review of bridge scour monitoring techniques', J Rock Mech Geotech Eng, 6, 2014.

[7] FHWA, Evaluating scour at bridges, HEC 18, HIF-12-003, 2012.

[8] N. Tanasić, R. Hajdin, 'Management of bridges with shallow foundations exposed to local scour', Struct Infr Eng, 14(4), 2018.

[9] COE, 'Climate change adaptation and disaster risk reduction in Europe' United Nations Office for Disaster Risk Reduction, 73p, 2011.

[10]FHWA 'Risk-Based transportation asset management: building resilience into transportation. Report 5'. US DoT, 2013.

[11]I. Gidaris, et al., 'Multiple-hazard fragility and restoration models of highway bridges for regional risk and resilience assessment. J of Struct Eng, 143(3), 2017.
[12]Institute of Hydrology, 'Flood Estimation Handbook', 5 volumes, Wallingford, 1999.

[13]S. Argyroudis, S.A. Mitoulis, M. Winter, AM. Kaynia, 'Fragility of transport assets exposed to multiple hazards: State-of-theart review toward resilience', Reliab Eng \& Syst Saf (accepted), 2019.

[14]V. Yuan, S. Argyroudis, E. Tubaldi, M Pregnolato, S. Mitoulis, 'Fragility of bridges exposed to multiple hazards and impact on transport network resilience', SECED2019, Greenwich, Sept 9-10, 2019.

[15]I. Kilanitis, A. Sextos, 'Integrated seismic risk and resilience assessment of roadway networks in earthquake prone areas', Bull Earthq Eng, 17(1), 181-210, 2019.

[16]R. Lamb, W. Aspinall, H. Odbert, T. Wagener, 'Vulnerability of bridges to scour: insights from an international expert elicitation workshop', Nat. Hazards Earth Syst. Sci., 17, 1393-1409, 2017.

[17]K.E. Train, 'Discrete choice methods with simulation', Cambridge Uni Press, 2003.

[18]C. Du, D. Kurowicka, RM. Cooke, 'Techniques for generic probabilistic inversion', Computational Statistics \& Data Analysis, 50(5): 1164-1187, 2006.

[19]B. Dodov, E. Foufoula-Georgiou, 'Generalized hydraulic geometry: derivation based on multiscaling formalism', Water Resour Res, 40(6), 2004.

[20]T.M. Modrick, K.P. Georgakakos, 'Regional bank-full geometry relationships for southern California mountain streams', Geomorphology, 221, 242-260, 2014.

[21]D.J. Booker, 'Predicting wetted width in any river at any discharge'. Earth Surf Processes \& Landforms, 35(7), 828-841, 2010.

[22]G. Wharton, 'Flood estimation from channel size: guidelines for using the channel-geometry method'. Applied Geography, 12(4), 339-359, 1992.

[23]P.J. Soar, C.R. Thorne, 'Channel restoration design for meandering rivers', $\mathrm{ERDC} / \mathrm{CHL}$ CR-01-1. US Army Corps of Eng, 2001. 